\title{
Article
}

\section{The Interpersonal Style and Complementarity Between Crisis Negotiators and Forensic Inpatients}

Dewa, Lindsay H., Ireland, Carol Ann and Gredecki, Neil Available at http://clok.uclan.ac.uk/2265/

Dewa, Lindsay H., Ireland, Carol Ann ORCID: 0000-0001-7310-2903 and Gredecki, Neil (2011) The Interpersonal Style and Complementarity Between Crisis Negotiators and Forensic Inpatients. Journal of Family Violence, 26 (4). p. 277. ISSN 0885-7482

It is advisable to refer to the publisher's version if you intend to cite from the work. http://dx.doi.org/10.1007/s10896-011-9363-7

For more information about UCLan's research in this area go to http://www.uclan.ac.uk/researchgroups/ and search for <name of research Group>.

For information about Research generally at UCLan please go to http://www.uclan.ac.uk/research/

All outputs in CLoK are protected by Intellectual Property Rights law, including Copyright law. Copyright, IPR and Moral Rights for the works on this site are retained by the individual authors and/or other copyright owners. Terms and conditions for use of this material are defined in the policies page.

\section{CLoK}

Central Lancashire online Knowledge www.clok.uclan.ac.uk

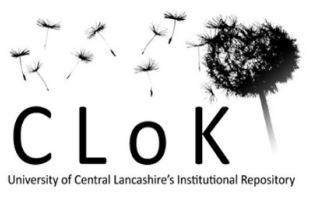


The Interpersonal Style and Complementarity between Crisis Negotiators and Forensic Inpatients

Lindsay H. Dewa

Carol A. Ireland*

Department of Psychology, University of Central Lancashire, Preston, United Kingdom

Neil Gredecki

Department of Psychology, University of Central Lancashire, Preston, United Kingdom

*Address correspondence to: Dr. Carol A. Ireland, Department of Psychology,

University of Central Lancashire, Preston PR1 2HE, United

Kingdom.

E-mail address CAIreland@uclan.ac.uk

Tel: 07990971923

Fax: 08716615401 


\begin{abstract}
Previous negotiation research has explored the interaction and communication between crisis negotiators and perpetrators. A crisis negotiator attempts to resolve a critical incident through negotiation with an individual, or group of persons in crisis. The purpose of this study was to establish the interpersonal style of crisis negotiators and complementarity of the interpersonal interaction between them and forensic inpatients. Crisis negotiators, clinical workers and students $(n=90)$ used the Check List of Interpersonal Transactions-Revised (CLOIT-R) to identify interpersonal style, along with eight vignettes detailing interpersonal styles. Crisis negotiators were most likely to have a friendly interpersonal style compared to the other non-trained groups. Complementarity theory was not exclusively supported as submissive individuals did not show optimistic judgments in working with dominant forensic inpatients and vice versa. Exploratory analysis revealed that dominant crisis negotiators were optimistic in working with forensic inpatients with a dominant interpersonal style. This study provides insight into the area of interpersonal complementarity of crisis negotiators and forensic inpatients. Whilst further research is required, a potential new finding was established, with significant 'similarity' found when dominant crisis negotiators are asked to work with dominant forensic inpatients.
\end{abstract}

KEYWORDS: Crisis negotiators, interpersonal style, forensic patients, Complementarity 
In crisis situations, such as hostage taking, a crisis negotiator's main focus is to ascertain a safe outcome for all involved. It can be suggested that effective, correct communication is one of the most important components in achieving this (Taylor, 2002). Effective communication can be achieved as a result of a complementary match between the negotiator's interpersonal style and that of the perpetrator. The importance of the crisis negotiator's interpersonal style when interacting with forensic inpatients as part of a crisis has previously been overlooked. Moreover, recruiters of potential crisis negotiators have targeted those who possess indiscriminate positive, friendlysubmissive interpersonal styles (Bailey \& Ireland, 2006), rather than being open to the impact of varying interpersonal styles of the negotiator.

Crisis negotiation has been part of law enforcement for many years, and has been employed as the primary tactic in intervening and resolving critical incidents throughout the world (Dolink, 2004; Ireland \& Vecchi, 2009; Vecchi, 2009). In negotiation research, there has been some confusion among researchers about what crisis negotiation actually is, due to the interchangeable terminology between 'crisis negotiation’ and 'hostage negotiation’ (Ireland \& Vecchi, 2009). Subsequently, for the purposes of clarity and consistency, this paper will employ the term 'crisis negotiation' to denote all critical incidents previously defined under both terms.

A critical incident can be defined as a "significant event that negatively disrupts the functions of everyday living and which requires the attention and expertise of those who are specially trained to handle these events” (Vecchi, 2009, p. 34). Critical incidents consist of individuals with high emotional levels and are managed through the 
facilitation of crisis negotiation using verbal communication strategies. Critical incidents involving the crisis negotiator and perpetrator can be defined under two separate terms: 'high conflict', where the perpetrator involved is of a rational mind and usually has a clear goal or outcome to obtain from the situation; or 'crisis situation', where the individual is irrational and has no intention of resolving the situation (Vecchi, 2009).

When applying this to mental disorder, effective communication is one of the most important components in achieving a safe outcome for both the crisis negotiator and mentally disordered perpetrator (Slatkin, 2005; Taylor, 2002). There is no empirical evidence available to identify the exact manner in which crisis negotiators should deal with mentally disordered offenders within a secure setting (Ireland, 2007). However, there is a vast quantity of research that focuses on how to identify and negotiate with individuals who present with mental disorder (Rogan, 2009), and which provides evidence to substantiate the linkage from the community to forced-environments such as a secure forensic hospital. Feldmann (2001) found that 19\% of perpetrators involved in a crisis situation showed evidence of a mental disorder including emotionally driven disorders such as depression (22\%), antisocial borderline disorder (20\%), and borderline personality disorder (9\%).

\section{Interpersonal Theory}

Interpersonal theory was derived from early theorists who identified the importance of the social context and relationships (Sullivan, 1953). It was then further developed to recognize personality and interpersonal behavior (Leary, 1957). Interpersonal theory is 
composed of three areas that are very closely related: interpersonal rigidity, interpersonal circumplex, and interpersonal complementarity. The main concept of each area is the importance of interpersonal behavior such as the corresponding dominance and submission. Exploring interpersonal behavior is important in the context of this paper as the core part of a crisis negotiation is the interaction between the crisis negotiator and the perpetrator.

It is acknowledged that interpersonal behavior explores the interactional behavior of two or more individuals rather than looking at the behavior of individuals separately (Kiesler, 1996). Therefore, it is not about the action of the individual that gives insight into their behavior, but rather their reaction to the other individual's action, better known as an interaction. For example, an interaction between two individuals can result where a dominant action from one individual invites a submissive action from the other.

The main concept of interpersonal complementarity, one of the three strands of interpersonal theory, is that the interaction between two people should complement each other's interpersonal style to achieve and maintain an interaction (Butt, Choi, \& Jaeger, 2005). This concept is important as it suggests that the interaction between two individuals will help authenticate each individual's presentation of behavior to each other. A person's interpersonal style of hostile-dominant behavior, such as being competitive, should invite hostile-submissive behavior, such as withdrawing from attention from the other person. Whereas a friendly-dominant act, for example seeking others company, should pull a friendly-submissive reaction, such as avoiding challenges (Blackburn, 1998; Kiesler \& Auchbach, 2003). The complementarity concept was 
further identified in patients with a personality disorder (Blackburn, 1998). Further, psychiatric patients with inflexible and rigid interpersonal styles have been found to comprise the same parts of the interpersonal circle regardless of the situation, whereas individuals with no evidence of mental disorder can vary their style depending on the situation (Pincus \& Gurtman, 2006). There have been some alternative views to the complementarity theory, such as the 'similarity' hypothesis (e.g., Barry, 1970; Blankenship, Hnat, Hess, \& Brown, 1984), with specific emphasis on how individuals with the same personality characteristics 'like' individuals with the same characteristics as themselves.

The Interpersonal Circle (circumplex) has had much attention in personality research over the past 60 years (Carson, 1969; Leary, 1957; Wiggins, 1979; Wiggins \& Trappnell, 1996), assessing the interpersonal style of non-disorder individuals, psychiatric patients (personality disorders; Soltz, Budman, Demby, \& Merry, 1993; Topf, Dambacher, \& Roper, 1979) and forensic psychiatric patients (Blackburn \& Renwick, 1996). Each interpersonal style can be mapped upon the interpersonal circle where interpersonal styles are made up of a blend of dominance and nurturance (friendliness) (Kiesler, 1983). Abnormal and 'normal' personality traits lie on a continuum (Kiesler \& Auchbach, 2003; Pincus \& Gurtman, 2006) and can therefore be measured on the same mutual dimensions of the interpersonal circle.

It can be suggested that the interpersonal style of the forensic inpatient should reflect the crisis negotiator's style. Milner (2002) created a thorough competency list of skills, abilities and personal characteristics considered fundamental to crisis negotiators. 
Examples of the types of qualities expected are as follows: adaptability, impartiality, objectivity, and self assuredness. There is no research on how the crisis negotiator's 'style' can be just as important as the style of the mentally disordered individual in order to obtain a positive interaction and a subsequent effective crisis negotiation situation and outcome. Based on an exploratory proposition, it can be suggested that crisis negotiators are friendly and positive in their crisis negotiation approach with all types of forensic inpatient (Bailey \& Ireland, 2006) and, as such, are deemed friendlysubmissive in their interpersonal style. In agreement with Gredecki's (2008) recognition of literature that identifies positive interpersonal styles of prison officers and prisoners within a prison setting, this study suggests that the assumption of the indiscriminate friendly/positive approach towards forensic inpatients challenges interpersonal complementarity theory. It can be argued that complementing interpersonal style will encourage better interaction (Gredecki, 2008) rather than limiting the success of a relationship by recruiting crisis negotiators with a similar interpersonal style.

This research study intends to investigate the interpersonal relationship (Leary, 1957) between the negotiator and the forensic inpatient, examining the complementarity (Carson, 1969; Kiesler, 1996) of the dyad. In addition, it aims to ascertain the interpersonal style of the crisis negotiator and whether it is different from clinical staff and the student population in an attempt to identify potential recruitment possibilities for crisis negotiators. 


\section{METHOD}

\section{Participants}

There were 90 participants in total. The study selected 31 trained crisis negotiators working at a high secure forensic hospital and 32 non-clinical staff from the same hospital. In addition, 27 psychology undergraduate students were randomly selected from a canteen or lecture theatre by informally asking for volunteers to complete the research project. The three groups $(n=90)$ were given all eight vignettes detailing the different interpersonal styles (Kiesler, 1996a; see Table 1). The vignettes only differed on interpersonal style of the patient: dominant (90), hostile-dominant (90), hostile (90), hostile-submissive (90), submissive (90), friendly-submissive (90), friendly (90) and friendly-dominant (90). Ethical approval was gained from NHS ethics and the University of Central Lancashire ethics committee.

\section{Measures}

The Check List of Interpersonal Transactions-Revised (CLOIT-R; Kiesler, 1984, 1987)

The Check List of Interpersonal Transactions-Revised (CLOIT-R; Kiesler, 1984, 1987) was used to assess the interpersonal style of all participants. CLOIT-R is a self-report measure that specifically examines the interpersonal actions to a target person (Kiesler, 2004) based on statements about that person. The questionnaire lists 96 statements that describe possible reactions to another person when in their company. Examples of the statements used are as follows: I am unwaveringly tolerant, patient, or lenient in regard to my expectations for their conduct (Item 30). Participants will conclude whether a 
description is a typically exhibited action of the participant about an interaction with another.

\section{Vignette}

Participants were asked to study eight vignettes describing an interpersonal style of a patient involved in a hostage incident, based on Kiesler’s (1996a) interpersonal definitions of submissive, friendly-submissive, hostile-submissive, hostile, friendly, dominant, hostile-dominant, and friendly-dominant. A seven-point Likert scale ranging from extremely difficult (1) to extremely easy (7) was used. An example of the dominant vignette (Gredecki, 2008) for the study is as follows:

Patient $A$ is a forensic inpatient residing in a secure hospital. He is currently involved in a crisis incident (e.g. hostage taking/barricade situation).

Patient A is self reliant, remains composed, asserts self, "toots own horn" (i.e. sings one's own praises), persuades others, takes charge, instructs and gives advice, and stands up to others.

"How easy is it to work with this patient involved in a crisis incident?"

This was repeated for all eight interpersonal styles. 


\section{Procedure}

The participants completed The Check List of Interpersonal Transactions-Revised (CLOIT-R; Kiesler, 1984, 1987). They then examined all eight vignettes and scored them using a Likert scale to indicate the perception of ability to work with the patient. Debriefing was provided.

\section{RESULTS}

\section{Reliability}

Reliability tests of the 96 items of the CLOIT-R scale was explored. Utilising Kuder Richardson analysis, CLOIT-R was revealed as a reliable scale with a coefficient of .83 indicating a high level of internal consistency.

\section{Interpersonal styles and participant groups}

Prior to the main analysis it was essential to screen the data effectively to be sure that the data analysis was correct. A range of tests were utilised to screen the data, including the checking of outliers, homogeneity of variance and parameters of parametric and non-parametric data. Kolmogorov-Smirnov Normality and Kruskal-Wallis tests were used.

\section{Interpersonal Styles}

A Kruskal-Wallis test showed that the difference between the groups (crisis negotiators, clinical workers and students) in dominant, hostile-dominant, hostile, hostile-submissive and friendly-dominant interpersonal styles were non-significant (all $\chi(2)=<4.078)$. 


\section{Submissive Interpersonal Style}

A Kruskal-Wallis test revealed a statistically significant difference in submissive interpersonal style across the three participant groups $(\chi(2)=10.656, p<.01)$. Students were more submissive than clinical workers or crisis negotiators.

\section{Friendly-Submissive Interpersonal Style}

A one way analysis of variance between subjects design revealed that there was a statistically significant difference on having a friendly-submissive interpersonal style between trained and untrained groups $\left(F(1,88)=7.528, p<.01\right.$, eta $\left.{ }^{2}=.08\right)$, showing that it was statistically more likely that crisis negotiators had a friendly-submissive interpersonal style.

\section{Friendly Interpersonal Style}

A one-way analysis of variance showed that there was a non-significant difference between the three participant groups on friendly interpersonal style $(F(2,87)=2.132$, $p>.05$, eta $\left.^{2}=.05\right)$. The non-existent significant difference illustrates that being trained in crisis negotiation or what group participants belongs to, is not attributable to having a friendly interpersonal style.

Dominant, Submissive, Hostile and Friendly Hemispheres of the Interpersonal Styles of Forensic Inpatient

[TABLE ONE HERE] 
Based on interpersonal theory (Leary, 1957) and Carson's (1969) interpersonal complementarity theory, where it was hypothesized that dominance invites submission and vice versa, a one-way analysis of variance showed that the difference between participants with a dominant interpersonal style and forensic inpatients with an interpersonal style within the submissive hemisphere was non-significant $(F(10,79)=$ 1.854, $p>.05$ eta $^{2}=.19$ ). Likewise, a one way analysis of variance showed that there was no significant difference between participants with submissive interpersonal style and forensic inpatient's interpersonal style that fell in the dominant hemisphere $(F(10,79)=$ $.808, p>.05$, eta ${ }^{2}=.09$ ). This indicated that dominant participants were not optimistic about working with submissive forensic inpatients.

Based on Leary's (1957) concept of hostility pulling hostility and friendly pulling friendly, a one-way analysis of variance revealed that there was a non significant difference between hostile interpersonal style of participants and the hostile hemisphere $\left(F(9,80)=1.120, p>, 05\right.$, eta $\left.{ }^{2}=.11\right)$. Results showed that hostile participants were not optimistic about working with hostile forensic inpatients.

It was further hypothesized that participants with a friendly interpersonal style would be more optimistic about working with forensic in-patients with a friendly interpersonal style. A one-way analysis of variance was performed showing that there was a nonsignificant difference between participants with a friendly interpersonal style and forensic inpatients with an interpersonal style within the friendly hemisphere $(F(17,72)$ 
$=.510, p>.05$ eta $^{2}=.11$ ), showing that friendly participants were not optimistic about working with friendly forensic inpatients.

\section{[TABLE TWO HERE]}

A one-way analysis of variance showed that the prospect of crisis negotiators with a submissive interpersonal style working with forensic inpatients with an interpersonal style within the dominant hemisphere was not significantly optimistic $(F(6,24)=1.693$, $p>.05$, eta $\left.^{2}=.29\right)$.

A one-way analysis of variance was performed to investigate the complementarity between submissive hemisphere for forensic inpatients and dominant interpersonal style of crisis negotiators. A one-way analysis of variance revealed that crisis negotiators with a dominant interpersonal style did not report significantly more optimistic perceptions on working with forensic inpatients with an interpersonal style within the submissive hemisphere $\left(F(6,24)=2.393 p>.05\right.$, eta $\left.{ }^{2}=.37\right)$.

A one-way analysis of variance was utilized to examine interpersonal theory (Leary, 1957) that friendliness invites friendliness between crisis negotiators and forensic inpatients. A one-way analysis of variance revealed that there was not a significantly higher number of optimistic judgments made by crisis negotiators with a friendly interpersonal style on working with forensic inpatients within the friendly hemisphere $\left(F(14,16)=.461, p>.05\right.$, eta $\left.^{2}=.29\right)$. 
As part of further exploratory analysis, complementarity of crisis negotiators with a dominant interpersonal style was examined to determine how optimistic they were about working with forensic inpatients of the same style. A one-way analysis of variance revealed that crisis negotiators with a dominant interpersonal style displayed significantly more optimistic judgments of working with forensic inpatients with a interpersonal style within the dominant hemisphere $\left(F(6,24)=.3 .934, p<.01\right.$, eta $\left.{ }^{2}=.50\right)$.

\section{DISCUSSION}

This is the first research study looking at the interpersonal relationship between crisis negotiators and forensic inpatients within the forced-contact environment (Gredecki, 2008) of a secure forensic hospital. Submissive interpersonal style demonstrated a difference between crisis negotiators, clinical workers and students. Friendlysubmissive interpersonal style was found to be different across the three participant groups, whereas the remaining interpersonal styles were not significantly different across the groups. Being trained in crisis negotiation was predictive in having a friendly-submissive interpersonal style when compared to the non-trained groups. Subsequent analysis revealed that dominant individuals did not display positive judgments in working with submissive forensic inpatients. Similarly, submissive individuals were not optimistic about working with dominant forensic inpatients. Dominant crisis negotiators were more optimistic about working with forensic inpatients with an interpersonal style that fell in the dominant hemisphere. Friendly and hostile hemispheres did not display complementarity with the corresponding interpersonal styles of forensic inpatients. 
Interpersonal complementarity theory suggests that hostility invites hostility and friendliness invites friendliness (Blackburn, 1998; Carson, 1969; Kiesler, 1996; Kiesler \& Auchbach, 2003). This study illustrates that the original theories based around the interpersonal circumplex (Leary, 1957) and interpersonal complementarity (Carson, 1969) were not supported as significant corresponding and reciprocal responses between participants (crisis negotiators, clinical workers and students) and forensic inpatients did not occur. In addition, there was no complementarity between an individual's friendly interpersonal style and forensic inpatients with an interpersonal style within the friendly hemisphere of the Interpersonal Circle 1982 (Kiesler, 1983). Moreover, subsequent analysis conducted specifically on crisis negotiators revealed there was also no complementarity of friendliness across the affiliation axis of the interpersonal circle. However, all participants were more optimistic about working with forensic inpatients with an interpersonal style within the friendly hemisphere than any other hemisphere, including the hostile hemisphere.

Research shows that friendliness is common in all individuals and often happens regardless of the interpersonal style of the other person (Topf, Dambacher, \& Roper, 1979). Therefore, it is possible that this is the reason participants were most likely to display a friendly interpersonal style. Furthermore, it also likely that the reason that there was no corresponding complementarity between hostile hemisphere and hostile interpersonal style, and friendly hemisphere and friendly interpersonal style, was that friendliness was observed to be more prominent than hostility. This indicates that participants exhibiting a friendly interpersonal style were friendly regardless of the forensic inpatient's interpersonal style. Whereas, if friendly base rates were controlled 
for, it is possible that participants with a friendly interpersonal style would reconsider their positive judgments against hostile, dominant, and submissive forensic inpatients. Consequently, controlling for friendliness may make the influence of complementarity more visible.

The current study found that trained crisis negotiators are actually more likely to have a friendly interpersonal style compared to the other styles; however, crisis negotiators were still more likely to have a friendly-submissive interpersonal style than the other participants, which was in agreement with the original hypothesis. Nevertheless, clinical workers and students were also more likely to have a friendly and friendly-submissive interpersonal style than any other interpersonal style. It was hypothesized that being trained in crisis negotiation has an effect on the responses employed upon CLOIT-R measure, with results showing that the majority of answers leaned towards friendly and friendly-submissive interpersonal styles. Yet, as the clinical workers and students were also most likely to be friendly, it can be argued that being trained in crisis negotiation does not affect interpersonal style or judgments when interacting with others. Yet, it is possible that the role of crisis negotiators seemingly determined through the crisis negotiator training (Bailey \& Ireland, 2006), merely draws clinical staff who have friendly interpersonal styles.

In this study, complementarity (Carson, 1969) did not exist between participants or crisis negotiators with a submissive interpersonal style and forensic inpatients with an interpersonal style within the dominant hemisphere as participants were not significantly optimistic about working with the forensic inpatients. In addition, in the 
present study, participants in general were more optimistic about working with forensic inpatients with an interpersonal style within the submissive hemisphere than the dominant hemisphere. Nevertheless, an unexpected result occurred which challenged complementarity theory. Dominant crisis negotiators were optimistic about working with forensic inpatients with a dominant interpersonal style determined by the interpersonal style definitions. This result went against complementarity theory; instead it supported the 'similarity’ hypothesis (e.g., Barry, 1970; Blankenship, Hnat, Hess, \& Brown, 1984), with specific emphasis on how individuals with the same personality characteristics 'like' individuals with the same characteristics as themselves. It is possible, therefore, that contrary to the complementarity view that crisis negotiators with a dominant interpersonal style are more optimistic about working with forensic inpatients with a submissive interpersonal style, dominant crisis negotiators are more likely to be optimistic about working with dominant forensic inpatients.

As previously mentioned, no research has been conducted which explored the interpersonal style, interaction and complementarity of crisis negotiators and forensic inpatients. Therefore, the results of this study are unique to crisis negotiation research. Future research in the investigation of interpersonal complementarity in the dyad of crisis negotiator and forensic inpatient is necessary to understand their relationship further. While the results bring about the further research possibility of interpersonal style specific recruitment of crisis negotiators and the relationship with forensic inpatients, there are a few short falls that need to be addressed, including the exploration of individual differences by using a broad spectrum of behavioral analysis and a larger sample size of crisis negotiators. Yet, despite this, there are implications of these 
findings. Acknowledging that the majority of crisis negotiators either have a friendly or friendly-submissive interpersonal style, and that they were the most optimistic with forensic inpatients who displayed an interpersonal style within the friendly hemisphere, puts forward a platform for a more robust recruitment system and targeting of candidates that are suitable to be trained in crisis negotiation. This suggests that it is possible that similar interpersonal styles can be matched to ascertain the safest outcome in a crisis situation. Therefore, it can be argued that a range of crisis negotiators should be recruited based on their interpersonal style which should be similar to the forensic inpatient's interpersonal style. Overall, more research is required to support or deny complementarity theory and the 'similarity' hypothesis.

\section{REFERENCES}

Bailey, K. and Ireland, C.A. (2006). Basic Crisis Negotiation Manual. Liverpool: Mersey Care NHS Trust and Partnerships in Care.

Barry, W. A. (1970). Marriage research and conflict: An integrative review. Psychological Bulletin, 73(1), 41-54.

Blackburn, R. (1998). Psychopathy and the Contribution of Personality to violence. In

T. Millon, E. Simonsen, M. Birket-Smith and R. Davis Psychopathy: Antisocial, Criminal and Violent Behavior (pp.50-68). 
Blackburn, R. and Renwick, S.J. (1996). Rating Scales for Measuring the Interpersonal Circle in Forensic Psychiatric Patients, Psychological Assessment, 8, 76-84.

Blankenship, V., Hnat, S.M., Hess, T.G. and Brown, D.R. (1984). Reciprocal interaction and similarity of personality attributes. Journal of Social and Personal Relationships. 29, 415-432.

Butt, A.N., Choi, J.N. and Jaeger, A.M. (2005). The effects of self-emotion, counterpart emotion, and counterpart behavior on negotiator behavior: a comparison of individuallevel and dyad-level dynamics. Journal of Organizational Behavior. 26, 681-704.

Carson (1969). Interaction concepts of personality. Chicago: Aldine.

Dolink, A. (2003). Contrasting dynamics of crisis negotiations: barricade versus kidnapping incidents. International Negotiation, 8, 495-526.

Feldmann, T.B. (2001). Bipolar disorder and violence. Psychiatric Quarterly, 72, 119129.

Gredecki, N. (2008). Applications of Interpersonal Circumplex \& Complementarity Theory to Staff-Prisoner Relationships. Unpublished research paper, Merseyside: Merseycare NHS Trust. 
Ireland, C.A. (2007). Crisis negotiation with a mentally disordered offender population: Development of a training package in a high secure forensic hospital. Forensic Update 91 Autumn, 19-26.

Ireland, C.A. and Vecchi, G.M. (2009). Crisis negotiation, Perpetrator characteristics, management and terrorism the behavioral influence stairway model (BISM): a framework for managing terrorist crisis situations? Journal of the International Society for Terrorism Research, 1 (3), 203 - 218.

Kiesler, D.J. (1983). The 1982 Interpersonal Circle: A Taxonomy for complementarity in Human Transactions. Psychological Review, 90, 185-214.

Kiesler, D.J. (1996). Contemporary Interpersonal Theory and Research. Personality, Psychopathology, and Psychotherapy. New York: Wiley.

Kiesler, D.J. and Auerbach, S.M. (2003). Integrating measurement of control and affiliation in studies of physician-patient interaction: the interpersonal circumplex. Social Science and Medicine, 57, 1707-1722.

Leary (1957). Interpersonal Diagnosis of Personality. New York: Ronald Press.

Milner, C (2002). The Crisis Negotiator: An exploratory study of the skills, abilities and personal characteristics of an effective negotiator. University of Surrey, unpublished MSc Dissertation. 
Pincus, A.L. and Gurtman, M.B. (2006). Interpersonal Theory and the Interpersonal Circumplex: Evolving Perspectives on Normal and Abnormal Personality. In S. Strack (Ed.), Differentiating Normal and Abnormal Personality 2nd Ed. (pp.83-112).

Rogan, R.G. (2009). Linguistic indicators of suicidality in crisis negotiations. Journal of Police Crisis Negotiations, 9, 34-54.

Slatkin, A.A. (2005). Communication in Crisis and Hostage Negotiations: Practical Communication Techniques, Stratagems, and Strategies for Law Enforcement, Corrections and Emergency Service Personnel in Managing Critical Incidents. Springfield: Charles C Thomas Publisher LTD.

Soltz, S., Budman, S. Demby, A. and Merry, J. (1993). Representation of personality disorders in circumplex and five-factor space: explorations with a clinical sample, Personality Assessment, 5, 41-52.

Sullivan, H.S. (1953). The Interpersonal Theory of Psychiatry, New York, Norton Taylor, P.J. (2002). A cylindrical model of communication behavior in crisis negotiations. Human Communication Research, 28, 7-48.

Topf, M., Dambacher, B. and Roper, J. (1979). Quality of Interpersonal Style among Hospitalized Psychiatric Patients. Western Journal of Nursing Research, 1, 163-170. 
Vecchi, G.M. (2009). Conflict and crisis communication: a methodology for influencing and persuading behavioral change. Behavioral Sciences, Spring, 34-42.

Wiggins, J.S. (1979). A psychological taxonomy of trait-descriptive terms: The interpersonal domain. Journal of Personality and Social Psychology, 37, 395-412.

Wiggins, J.S. and Trapnell, P.D. (1996). A dyadic-international perspective on the fivefactor model. In J.S. Wiggins (Ed.), The five-factor model of personality: Theoretical perspectives (pp. 82-162). New York: Guilford Press. 
Table 1 - Descriptive statistics of vignette scores given by participants for forensic inpatients in each hemisphere

Mean SD.

\begin{tabular}{llll}
\hline \hline Dominant hemisphere (forensic inpatient vignettes 1, 2, 3, 7, 8) & 18.41 & 4.31
\end{tabular}

Submissive hemisphere (forensic inpatient vignettes 3, 4, 5, 6, 7) $22.00 \quad 3.94$

Hostile hemisphere (forensic inpatient vignettes 1, 2, 3, 4, 5) $\quad 17.56 \quad 4.80$

Friendly hemisphere (forensic inpatient vignettes 1, 5, 6, 7, 8) $23.10 \quad 4.15$

Table 2 - Descriptive statistics of the vignette scores given by crisis negotiators for forensic inpatients in each hemisphere

\begin{tabular}{llc}
\hline & Mean & SD. \\
\hline \hline Dominant hemisphere (forensic inpatient vignettes 1, 2, 3, 7, 8) & 17.42 & 4.98 \\
Submissive hemisphere (forensic inpatient vignettes 3, 4, 5, 6, 7) & 21.58 & 4.04 \\
Hostile hemisphere (forensic inpatient vignettes 1, 2, 3, 4, 5) & 16.35 & 4.90 \\
Friendly hemisphere (forensic inpatient vignettes 1, 5, 6, 7, 8) & 22.39 & 4.08 \\
\hline
\end{tabular}

